\title{
CURRÍCULO E INCLUSÃO ESCOLAR: (In)variantes educacionais e curriculares
}

José Augusto Pacheco ${ }^{(*)}$

\section{CURRÍCULO E INCLUSÃO EDUCATIVA EM CONTEXTOS DE GLOBALIZAÇÃO}

Há uma ideia generalizada, sustentada tanto por estudos teóricos e empíricos, como por professores, alunos e pais, e fortemente presente no senso comum, que a escola é um lugar de discriminação social. Desde os primeiros estudos, baseados na discriminação da escola, realizados, por exemplo, pelos norte-americanos Bowles e Gintis (1976) e pelos franceses Bourdieu e Passeron (1970), até à elaboração de dissertações e teses, a discriminação é uma realidade escolar inserida na organização escolar, sobretudo da abordagem do conhecimento. Com efeito, e no olhar crítico de Goodson (2001), os que detêm o poder tentam definir qual é o conhecimento mais válido na sociedade, havendo interesses divergentes no modo como os diferentes grupos sociais têm acesso a esse conhecimento, pelo que não são iguais as relações entre áreas de conhecimento, tal como os grupos sociais que dela beneficiam. Se a organização do conhecimento escolar começa pelo processo de transformação curricular (PACHECO, 2016), sendo completado pela transposição pedagógica (LIBÂNEO, 2012), se a apropriação desse conhecimento ocorre em contextos de práticas sociais, culturais e institucionais, que aparecem na escola "tanto como contexto social e cultural quanto como conteúdos, influenciando nas mudanças no desenvolvimento e na aprendizagem dos alunos" (p. 44), de que modo a inclusão pode ser tratada como princípio central de desenvolvimento do currículo, em particular, e da educação, em geral, de modo a evitar a exclusão dos alunos no acesso e no percurso escolar?

Quando a escola se torna um lugar de conhecimento poderoso (YOUNG, 2013; 2016), em que as disciplinas representam padrões sociais e culturais, com vista a manter uma correlação de forças existentes, determinada pela desigualdade entre grupos sociais, as práticas escolares são confrontadas a partir de duas perspetivas interrelacionadas, mas dicotómicas, na prática: educação e instrução. Sendo a educação um direito consagrado universalmente, no sentido do desenvolvimento do sujeito nas suas dimensões social, cultural e pessoal, e sendo a instrução a face escolar desse

\footnotetext{
${ }^{(*)}$ Professor Catedrático do Instituto de Educação da Universidade do Minho.E-mail: jpacheco@ie.uminho.pt.
} 
direito, por que razão a escola é cada vez mais um lugar de instrução e cada vez menos um lugar de educação?

Uma primeira resposta pode ser procurada na função meritocrática da escola, na sua organização para a transmissão e avaliação de um conhecimento tido como essencial para a distinção social das pessoas, mesmo que a igualdade e a inclusão sejam termos usados como definidores de uma escola centrada no desempenho pessoal. Há muitas metáforas utilizadas no currículo e avaliação para traduzir esta realidade de produção de desigualdade, aliás bem exploradas pelos teóricos do liberalismo que atribuem a centralidade ao sujeito ou indivíduo que é titular de direitos, "independentemente da sua função ou do seu lugar na sociedade, e que o tornam igual a qualquer outro homem". (MANENT, 2015, p. 9).

Duas dessas metáforas reportam-se, pelo menos, à escola como montanha a ser escalada individualmente, sabendo-se que nem todos conseguem chegar ao ponto mais alto, como se o ideal escolar estivesse situado no monte Everest, bem como ao currículo, tal como aparece na definição, do século XIX (GOODSON, 2001), como pista circular de corrida de cavalos, onde o competir significa chegar em primeiro e admitir o insucesso dos outros. Esta linguagem de competição, presente no ofício do aluno (PERRENOUD, 1995), tem eivado as práticas escolares em toda a sua organização, incluindo o modo como são apresentados o conhecimento e a aprendizagem. Para os seus defensores, situados nas teorias curriculares do racionalismo académico e da teoria de instrução, esta, ligada à racionalidade tyleriana, aquela, à noção de inteligência como músculo e à escola panótica (PACHECO, 2014), a exclusão é uma prática justificada, pois nem todos os indivíduos, apesar dos seus direitos naturais, se posicionam nos mesmos grupos sociais, têm os mesmos interesses perante a escola. Assim, o que se torna na base da aprendizagem escolar é o princípio do universalismo epistémico, afirmando-se, inclusive, que o conhecimento não é socialmente construído e que o construtivismo é uma deriva psicológica e pedagógica, orientado para a destruição da imagem clássica do conhecimento baseado em factos, na justificação e na explicação racional. Tais ideias são defendidas, de entre outros teóricos, por Boghossian (2015, p. 9), que escreve contra a formação do "consenso extraordinário - nas ciências sociais e humana e até nas ciências naturais - em torno de uma tese de que o conhecimento é socialmente construído". Se esta ideia fosse validada, a educação transformar-se-ia num processo mais radical de exclusão, argumento que de modo algum perfilhamos.

Uma outra resposta - e não é possível enumerar muitas mais neste artigo - que é a continuidade da primeira, está na utilização dos termos qualidade, eficácia e eficiência, no contexto 
de políticas de accountability e responsabilização. Mais do que uma abordagem supostamente ligada à inclusão, os novos termos são velhos termos, agora ressignificados pela globalização.

Deste modo, qualidade, eficiência, eficácia - no quadro de uma cultura de prestação de contas -, são termos que alteram por completo as políticas e práticas curriculares, com incidência na produção da exclusão escolar dos alunos, apesar de parecerem ser palavras simples, mas como diz Horkheimer (1944/2014, p. 95), “a preferência por palavras e frases simples, que podem ser agregadas de um só golpe, é uma das tendências anti-intelectuais, anti-humanistas, manifestas no desenvolvimento da linguagem moderna, bem como da vida cultural em geral”.

Na prática, a apropriação destes termos que são um dos pré-requisitos da performatividade, centrada no desempenho distinto dos alunos, insere-se no movimento de reforma global da educação, ou seja, direcionado para a estandardização, a prestação de contas, os testes à larga escala e a competição centrada na lógica de mercado, como reconhecem Hargreaves e Fullan (2012). As mudanças que se observam nas práticas curriculares "são claramente influenciadas pelas mudanças colossais que estão ocorrendo atualmente na economia global” (GOODSON, 2008, p. 26), com o reposicionamento do papel do professor e o seu questionamento na construção de um presente em que a escola pública é criticada como um legado histórico e um bem social, sendo as ideias de justiça social e democratização da escola criticadas, uma vez que seria o pensamento emancipatório a tornar-se numa abordagem ideológica indesejável (ADORNO, 1971/2011).

O mais correto politicamente para a escola, professores, alunos e encarregados de educação seria a existência de uma escola sem partido, isto é, sem ideologia ou um sistema de crenças, atitudes e comportamentos, que não pode deixar de existir tanto na sociedade, como na escola, sendo que existe uma concepção normativa da ordem simbólica, em relação ao qual o sujeito se refere e ao qual atribui a sua própria crença (ŽIŽEK, 2009). Trata-se, com efeito, de uma falsa ideia - e insustentável, por que não o afirmar? - para a educação e escola, por mais sentido de uniformização que fosse procurado para a formação dos alunos nos seus percursos curriculares.

Deste modo, o presente, marcado pelas políticas de prestação de contas e responsabilização, que reforçam a ideologia neoliberal e conservadora, marca, como argumenta Boff (2013), a passagem de uma economia de mercado para uma sociedade de mercado e só de mercado, com todas as consequências para a educação, em geral, e para o currículo, em particular. 
Neste caso, a escola como negócio ${ }^{1}$ surge na realidade educacional, quase indistintamente em todos os países ligados por uma globalização económica, com a entrega ao setor privado de serviços que são públicos, em nome da eficiência do mercado, tendendo a "ser tutelada de acordo com o modelo da linha de montagem fabril" (PINAR, 2007, p. 53) e originando no professor uma identidade de gestor empresarial, assim definido por Hargreaves e Fullan (2012, p. XIII): "limita o currículo, volta-se para a tecnologia, prescreve e segmenta a instrução, ensina para os testes, reduz a literacia a pequenos trechos de compreensão em vez de envolvimentos mais significativos através de textos absorventes".

Quer dizer, assim, que o professor será alguém mais preocupado com a implementação das políticas governamentais do que com as respostas que se torna necessário dar às necessidades dos alunos, apesar de as políticas nacionais, como é o caso português (SEABRA, 2015, p. 76), imporem a racionalização do currículo, retirando-lhe, entre outras áreas, a educação cívica, e "a criação de agrupamentos escolares, sem pôr em causa o acesso à educação" como método de reduzir as despesas em educação. Assim, reconhecer-se-á, que "foram objetivamente reduzidas as margens de participação das escolas e dos professores na concepção e na gestão do currículo" (ESTEVES, 2015, p. 327).

Consequentemente, nas políticas nacionais, traçadas por organismos transnacionais e supranacionais, onde são geradas as chamadas políticas de partilha de conhecimento (STEINERKHAMSI, 2012), instituintes de reformas viajantes, e de um modelo pós-burocrático (MAROY, 2012), são bem visíveis as formas de controlo do currículo - mais diretrizes, mais currículo prescrito, mais instrumentos de avaliação à larga escala e mais procedimentos de monitorização (THIESEN, 2015) -, com tendência para o reforço da gestão do currículo baseada numa cultura de avaliação orientada para a mensuração das aprendizagens, num contexto de exclusão, já que os alunos são situados em escalas de quantificação e o diploma é um passaporte social para a inclusão excludente.

Neste sentido, Santos (2015, p. 237) escreve que "é importante considerar que as matrizes de referência dos testes terminam reduzindo o currículo escolar àquilo que é mensurável, enquanto outros aspetos fundamentais do processo educacional são secundarizados ou até descartados”. A mensuração pressupõe, assim, a generalização de padrões de aprendizagem e o estímulo à

\footnotetext{
${ }^{1} \mathrm{O}$ negócio na escola consagra a lógica de mercado, declarando a gestão privada como a mais eficiente e eficaz, sendo exemplo disso as vouchers schools, nos Estados Unidos, o cheque-ensino, em muitos países, e os organismos sociais, no Brasil.
} 
competição que veicula uma ideologia do mérito, ou seja, uma pedagogia dos resultados e dos testes.

Tais efeitos, pela análise de Esteves (2015, p. 324), resultam das “políticas de mundialização que têm incluído, de forma flagrante e crescentemente visível, a educação", na medida em que se afirma o seu valor enquanto "mercadoria que se vende e compra no mercado global e em que se presume que os seus resultados, os seus produtos, são essenciais para o crescimento da economia, para o triunfo sobre a concorrência e para a competitividade" (p. 324).

Esta situação está presente na forma de fazer a gestão do currículo em função das políticas educativas transnacionais orientadas para a prestação de contas. Assim, a abordagem centrada nos testes é essencialmente definida pela abordagem centrada em resultados e pela abordagem centrada em standards, ou seja, "duas governamentalidades curriculares expressas nas práticas quotidianas curriculares, cada vez mais inseridas numa lógica empresarial para a educação, em normas concretas para a privatização das escolas, em dispositivos de avaliação externa e em práticas de mercadorização curricular" (PACHECO; MARQUES, 2014, p. 108).

Tais formas de governação curricular, que destacam, entre outros aspetos, o desempenho ao nível dos resultados, os testes à larga escala, com incidência nos testes transnacionais, de que o PISA é o padrão, o ranking de escolas e a linguagem das competências, uma outra forma de apresentar objetivos de aprendizagem e metas curriculares, originam não só uma escolarização restrita, que inclui o core curriculum e provoca o mimetismo curricular, ${ }^{2}$ como também a coerção avaliativa, em que a avaliação é marcada pela resultados entendidos como scores numa prática de competição, na base da qual estão processos explícitos e implícitos de exclusão.

Deste modo, o perfilhamento destas formas governamentalidade curricular confronta o professor com o que pode ser denominado recontextualização performativa, isto é, uma coerção avaliativa, quer ao nível da produção de discursos, quer no plano das práticas, que sobrepõe as questões técnicas às pedagógicas, nomeadamente, questões sobre a eficiência e eficácia do processo educacional” (BIESTA, 2013, p. 41). Tal processo de recontextualização inscreve-se, segundo Morgado (2014, p. 87), numa cultura de performatividade, originária de uma nova gramática e semântica que "veicula um profissionalismo controlado e relega os professores para a posição de

\footnotetext{
${ }^{2}$ Por mimetismo curricular entende-se a tendência para que as disciplinas nucleares do currículo, por exemplo, Matemática e Português, com formas predominantes de avaliação externa, sirvam de exemplo às restantes disciplinas.
} 
meros executantes das orientações gerais das políticas educativas", com incidência no modo como cada professor perspetiva a inclusão, ou seja, uma inclusão de resultados.

Como se tratasse de um pêndulo que oscila entre o transnacional e o nacional, a globalização define as políticas educativas através de conceitos-chave e impõe padrões para a sua implementação, não pelos processos, mas pelos resultados. Esta é, de facto, uma mudança substantiva com reflexos no modo de perspetivar a profissionalidade docente, como analisou Maria Teresa Estrela em muitos dos seus escritos (CAETANO; RODRIGUES; ESTEVES, 2015). Neste caso, "o professor ganhou uma autonomia profissional mais ampla, mas agora é responsabilizado pelos resultados, em particular pelo fracasso dos alunos" (CHARLOT, 2013, p. 99), trabalhando numa escola que é produtora de injustiças. Afirmar-se-á, assim, que a injustiça é uma característica estrutural da escola, aceitável no plano coletivo (FELOUZIS; MAROY; ZANTEN, 2013), pelo que a tendência é para que se utilize mais a linguagem da aprendizagem do que a linguagem da educação (BIESTA, 2013).

De mão dada com a globalização caminha a cultura de prestação de contas, que não para de crescer e que parece não ter fim, situando-se os professores "num movimento de pinça entre os pais e os burocratas" (HARGREAVES; FULLAN, 2012, p. 35), pois as políticas são cada vez mais “iniciativas administrativas fragmentadas, incoerentes e modistas” (p. 36).

Recorrendo-se aos mesmos autores, o currículo é estandardizado e por vezes é prescrito em detalhes excruciante, as escolas têm menos recursos, há turmas com mais alunos, há falta de tempo para o desenvolvimento profissional docente, exalta-se a importância dos testes, valoriza-se o ranking de escolas e as intervenções da inspeção escolar são mais rápidas e punitivas, para além de cultivar-se uma colaboração formal, burocrática e baseada em procedimentos administrativos. Como refere Arendt (2006, p. 154), “dá-se maior importância ao conhecimento prescrito pelo currículo do que às atividades extracurriculares".

Quer dizer, assim, que o currículo, pela sua vincada estandardização, tende para uma similaridade construída globalmente que configura a inclusão de resultados.

\section{EDUCAÇÃO INCLUSIVA}

É inegável que, apesar dos contornos negativos que têm no modo como contribuem para a estandardização das práticas sociais, nas quais se incluem as das escolas relativamente à inclusão, os organismos transnacionais, com destaque para Unesco, têm desempenhado um papel positivo na 
fixação de referenciais, geralmente traduzidos em metas, para uma democratização da educação, no que consagra os direitos de acesso de TODOS à educação e na garantia de uma educação de qualidade e diferenciada. É o caso da Declaração Mundial sobre Educação para Todos: Satisfação das Necessidades Básicas de Aprendizagem, de 1990, bem como da Conferência Mundial sobre Necessidades Educativas Especiais: Acesso e Qualidade, de 1994, documentos que reforçam o princípio da inclusão na educação, no reconhecimento que todas as pessoas, com a suas diferenças e necessidades individuais, não sejam segregadas quer no acesso à escola, quer no processo de desenvolvimento do currículo, que fixa os percursos escolares em função da sua diversificação organizacional.

Mais recentemente, verificou-se a aprovação, em 2015, pela ONU, dos Objetivos de Desenvolvimento Sustentável, sendo de destacar, respetivamente, o quarto e quinto objetivos: "Assegurar a educação inclusiva, equitativa e de qualidade, e promover oportunidades de aprendizagem ao longo da vida para todos" e "Alcançar a igualdade de género e empoderar todas as mulheres e meninas".

Quando são declarados princípios globais de orientação política, com efeitos no modo como é organizada a educação, olha-se mais para macro-aspetos do que propriamente para as questões educacionais concretas, nas quais participam TODOS os alunos. De facto, a escola inclusiva acolhe e educa uma enorme diversidade de alunos, nomeadamente: alunos oriundos de espaços culturais diversos; alunos com necessidades efetivas (cognitivas e físicas); alunos com diferentes contextos socioeconómicos; alunos com diferentes níveis de habilidades; alunos com dificulades de aprendizagem; alunos com diferentes destrezas sociais; alunos com diferentes valores e crenças; alunos com diferentes estilos de aprendizagem; alunos com diferentes níveis de desenvolvimento (comportamental, mental e físico); alunos dotados; alunos sexualmente diferentes; alunos com necessidades emocionais (MERGLER; CARRINGTON; KIMBER; BLAND, 2016; ALONSO; CASTEDO; JUSTE; VARELA, 2015).

Face a tal diversidade, a inclusão educativa, quando materializada em percurso escolar formal, inclui quer um processo de diversificação do currículo, com a delimitação de caminhos diferentes de aprendizagem, de acordo com níveis e ciclos de escolares e na base de opções ligadas a tipologias educacionais muito concretas, por exemplo, o ensino vocacional e o ensino especial diferenciado, quer uma prática de diferenciação curricular, que acontece na relação pedagógica e no espaço das salas de aula (SOUSA, 2010; ROLDÃO, 2003). 
Deste modo, e perante a diversidade com que a escola é confrontada na organização dos percursos escolares, que respondem a necessidades de públicos diferentes, o grande desafio é o de organizar o processo de desenvolvimento do currículo que seja democrático e inclusivo, sabendose, no entanto, que toda e qualquer forma escolar contém em si um potencial de discriminação, mais ainda se a escola usar a linguagem da instrução em detrimento da linguagem da educação. Pode-se dizer, por isso, que a discriminação é uma categoria criada a partir do interior da própria escola, ou seja, a escola, na forma como está organizada curricularmente, produz a desigualdade, não tanto no ponto de partida, mas essencialmente no ponto de chegada ou na conclusão de ciclos e níveis escolares, pelo que a democratização através da educação é um ideal que estará sempre confrontado com políticas e práticas de discriminação curricular.

No contexto das políticas curriculares, tendo como pontos de referência a igualdade/desigualdade e a homogeneização/diversificação, identificamos quatro possibilidades no processo de desenvolvimento do currículo (PACHECO, 2000).

Uma política igual e homogénea. Pretensão de igualizar os alunos de acordo com as exigências políticas e sociais da não-discriminação. Aceitar-se-ia que a escola tende para a homogeneização dos alunos quando terminam um nível ou ciclo de escolaridade.

Uma política curricular igual e diversificada. A igualdade é reconhecida como fator de legitimação social da escola e a diversificação é entendida como uma pluralidade de caminhos que não conduzam à discriminação e à desigualdade.

Uma política curricular diversificada e desigual. A diversificação é o pré-requisito para a desigualdade, sendo fomentada através da pretensa qualidade do sistema educativo, avaliada pelos indicadores dos resultados obtidos pelos alunos nos testes nacionais e do ranking das escolas em termos de classificação nacional dos alunos. A excelência da escola é a excelência dos resultados e não a dos processos.

Uma política curricular homogénea e desigual. Todos os alunos, in nomine, devem ter as mesmas condições de igualdade. Na prática, são confrontados com formas particulares de diversificação, que, pela sua natureza de remediação escolar e de medidas de combate à exclusão escolar, são o prolongamento de desigualdade criada pela prescrição do currículo.

Tais possibilidades, algumas das quais inconcretizáveis, conduzem a inclusão educativa para o campo da integração curricular, sendo necessário perspetivar o currículo como um jogo social, 
com regras próprias, construído nos seus aspetos formais e informais, com a meta do conhecimento. E sobre esta questão, coloca-se, de novo, a questão nuclear: Qual é o conhecimento mais valioso?

O modo de responder a esta pergunta valida ou não as políticas e práticas de diversidade curricular, ainda que a escola contenha intrinsecamente na sua organização a discriminação e desigualdade, isto é, um princípio não democrático, sendo que este é um dos principais desafios quando se problematiza a função de socialização da escola e sua muldimensionalidade em termos de saberes de que é feito o conhecimento.

\section{PARA UMA PROBLEMATIZAÇÃO DA INCLUSÃO A PARTIR DE INVARIANTES EDUCACIONAIS E CURRICULARES}

Tal como está organizada socialmente, sobretudo a partir do momento em se processa a apropriação pelo Estado da educação pública, há, pelo menos, quatro invariantes educacionais e curriculares, que tem persistido desde o século XIX no interior da escola, período em que esta se tornou num assunto nacional e com interesses marcadamente administrativos, até aos dias de hoje, e certamente no futuro, assim identificadas e descritas, na convicção que não existem de forma separada e que a sua análise conduz a uma visão ampla de educação e a uma noção de currículo como projeto diferenciador:

Inclusão/exclusão/integração. A educação e o currículo, em suas formas escolares, podem ser representadas como faces de uma mesma moeda, que fabricam a inclusão, a exclusão e a integração. Tendo como principal propósito a formação de um sujeito, no sentido emancipatório que lhe é atribuído por Adorno (1971/2011), a educação só pode ter como objetivo social a inclusão escolar e a integração de saberes, mesmo que, nas práticas escolares, ocorra um processo de exclusão, largamente estudado na sociologia da educação. No entanto, e dado a sua face discriminante, a escola, com o sucessivo alargamento da escolaridade obrigatória, tem criado "a esperança da promoção social para os estratos mais desfavorecidos. Esta dinâmica gripou. O sucesso escolar e a seleção das elites continuam amplamente determinadas pelo meio social de origem" (LIPOVETSKY, 2012, p. 38), pelo que a escola como máquina de integração social está avariada. A inclusão e integração são, assim, sinónimos de exclusão.

Igualdade/uniformização/plano. Esta invariante verifica-se na educação a partir do momento em que a escola e o currículo se tornam numa organização e num dispositivo, respetivamente, de responder coletivamente através de soluções baseadas na igualdade, como princípio liberal de organização da educação, na estandardização de processos e práticas escolares e num conceito de 
currículo como plano que contém as normas para a sua implementação. O fechamento do currículo, como dispositivo que veicula um conhecimento poderoso (YOUNG, 2013), origina formas claras de controlo na escola, onde o vigiar e o punir foucaultianos das mentes e dos corpos são apenas um dos lados mais visíveis, já que a escola é um iceberg cognitivo que discrimina pelo modo como se organiza e impõe standards de aprendizagem.

Identidade/diferença/sujeito. Por mais sistema centralizado que exista para a escola, com normas a serem decididas e implementadas a partir de uma lógica top-down, a educação é sempre o espaço de afirmação e desconstrução da identidade e diferença do sujeito, cuja relação com o processo de aprendizagem se verifica numa dimensão subjetiva (PINAR, 2015) e num contexto social (WIEVIORKA, 2002).

Diversificação/diferenciação/projeto. Como dimensão social e pessoal, a educação, com os seus percursos escolares e trajetos curriculares, jamais pode tornar-se num único caminho a ser percorrido por todos os alunos, existindo no seu percurso quer a diversificação de opções nas tipologias de ensino, quer a diferenciação no modo como a aprendizagem interseta cada aluno em si e o currículo se transforma em projeto, aberto a possibilidades construídas pelo aluno.

Tais invariantes coexistem de uma forma muito variada nos sistemas educativos e projetamse na organização do currículo e no seu processo de desenvolvimento, tornando-se referencias para a discussão da inclusão nas práticas escolares. Partindo de uma análise focada na filosofia moral, e numa crítica às ideias perfilhadas sobre a desigualdade económica, por Piketty, em $O$ Capital no Séc. XXI, Frankfurt (2016, p. 12) contesta a igualdade económica como ideal moral, uma vez que “eliminar a desigualdade de rendimentos não pode ser, em si, o nosso objetivo fundamental” e que o que é "moralmente importante é que cada um tenha o suficiente" (p. 15). O autor advoga, ainda, para não se cair na arbitrariedade: "temos de tratar os semelhantes de forma semelhante e os dissemelhantes de forma diferente" (p. 65).

Há aqui nestas ideias dois princípios distintos: o princípio da desigualdade ou da dissemelhança, justificado socialmente, como sendo a base moral da sociedade, pois nem todos estão nas mesmas condições; o princípio da suficiência ou da semelhança, para que haja o respeito por cada pessoa. Todavia, o autor não entra na análise das razões sociais e pessoais que tornam possível a desigualdade, evocando-a como princípio moral, forjada a partir do principio liberal que todos são iguais à partida, em termos de direitos, mesmo que isso signifique que uns conseguem ter mais que outros, não podendo, assim, ser iguais. A questão analisada teoricamente é uma, situada 
no plano da moral, mas focada socialmente é outra, porque a desigualdade está associada à pobreza. Uma outra questão é a ligação das tecnologias à produção da desigualdade (LUNARDI, 2015).

O reconhecimento da desigualdade (económica e social) não pode situar-se no mesmo nível de discussão quando é dito que a diversidade curricular é um dos princípios que promovem a inclusão social e a diferença, tanto pelas normas, existentes em políticas, processos e práticas educativas, quanto pelos significados atribuídos pelas pessoas ao que significa ser igual e diferente. Sobre isto, e recorrendo-se a Libâneo (2016),

cumpre esclarecer, antes de tudo, que o reconhecimento da diferença e, assim, da diversidade social e cultural da convivência humana, e de modo especial na escola, representa um imenso avanço na vida social. A diferença não é uma excepcionalidade, mas sim condição constitutiva de todos os seres humanos e nenhuma ação educativa pode ignorar isso. No entanto, cabe distinguir diversidade social e desigualdade social. A valorização do atendimento à diversidade não pode obscurecer a realidade das desigualdades sociais. Estas não decorrem das diferenças individuais e culturais, sendo fruto da injustiça social. Uma política educacional em que o atendimento à diversidade social é posto como objetivo prioritário do sistema educativo põe em segundo lugar o direito ao conhecimento escolar e, com isso, acaba promovendo desigualdade social. (p. 57-58).

Mais do que respostas, há muitas perguntas a fazer sobre a inclusão educativa, perspetivada a partir da diversidade curricular, sobretudo quando há invariantes que promovem a inclusão e a exclusão:

- De que modo é construído um currículo inclusivo?

- Diferentes formas de organização curricular originam a criação de grupos de heterogeneidade cultural?

- Como ultrapassar a diversidade curricular sem cair na produção de estigmatismos sociais?

- A educação inclusiva é exclusiva de públicos especiais?

A consideração destas perguntas, sempre problemáticas, porque não representam determinações e certezas, mas espaços abertos para um questionamento crítico, permitem argumentar que: i) a diversidade curricular, presente nas suas diferentes formas de diversificação e diferenciação, é um princípio nuclear para uma educação inclusiva; ii) uma prática de diversidade curricular significa admitir que a escola tem alunos diferentes em termos culturais, socioeconómicos e individuais; iii) a educação inclusiva será tanto ou mais reforçada quanto mais as práticas escolares forem marcadas pela diversidade curricular; iv) a escola tem de pautar-se por 
princípios éticos de igualdade, mesmo reconhecendo-se que a diversidade curricular não significa a defesa de um igualitarismo educacional; v) a diversidade curricular conjuga o que é comum com o que é singular, na observação de situações específicas ligadas a contextos e pessoas.

Contudo, quando se afirma que a diversidade implica a diferença não é possível concordar com uma escola orientada para a discriminação e injustiça social. Embora, nas suas dimensões organizacional, curricular e pedagógica, a diversidade seja um a matriz desejada para a escolarização, a desigualdade não pode ser um princípio educacional, nem moral nem pedagogicamente. Como escreve Rios (2011),

justiça é igualdade na diferença. Somos diferentes, homens e mulheres brancos e negros, adultos e crianças. Mas somos iguais em direitos, iguais no direito de ter direitos, de criar direitos. Somos, portanto, diferentes e iguais. O contrário de igual não é diferente. É desigual, e tem uma conotação social e política. A afirmação da identidade se dá na possibilidade da existência da diferença e na luta pela superação da desigualdade.” (p. 238-239).

\section{CONCLUINDO}

A inclusão educativa é, pela sua natureza de percursos, uma questão curricular que necessita de ser repensada a partir de invariantes educacionais e curriculares que existem nas práticas escolares, e que têm legitimado a discriminação social a partir de lógicas orientadas para uma inclusão de resultados, bem como na como na base de uma discussão que reconhece a diversidade como principio fundamental do desenvolvimento do currículo. Se o igualitarismo curricular é algo de impensável, o que significaria tratar o dissemelhante como semelhante, reconhecendo-se que a escola o faz pelas suas práticas de estandardização e homogeneização, dizer que a diversidade é a matriz curricular da escola, na busca de um permanente ideal de justiça social, significa reconhecer que a educação é um projeto amplo e diferente, que não pode tornar-se num pêndulo que oscila, invariavelmente, entre os lados da discriminação pessoal e da discriminação social, como se o lados da justiça e igualdade não existissem. 


\section{REFERÊNCIAS}

ADORNO, Theodor W. Educação e emancipação. São Paulo: Paz e Terra, 2011.

ALONSO, José D.; CASTEDO, António L.; JUSTE, Margarita; VARELA, Elia V. Integración o inclusíón: el dilema educativo en la atención a la diversidade. Revista Portuguesa de Educação, v. 28, n. 2, p. 31-50, 2015.

ARENDT, Hannah. A condição humana. Lisboa: Relógio D’Água, 2006.

BIESTA, Gert. Para além da aprendizagem. Educação democrática para um futuro humano. Belo Horizonte: Autêntica, 2013.

BOFF, Leonardo. A grande transformação na economia, nas políticas, na sociedade. Petrópolis: Editora Vozes, 2013.

BOURDIEU, Pierre; PASSERON, Jean-Claude. La reproduction. Éléments pour une théorie du système d'enseignement. Paris: Les Editions de Minuit, 1970.

BOWLES, Samuel; GINTIS, Herbert. Schooling in capitalist America. New York: Basic Books, 1976.

CAETANO, Ana Paula; RODRIGUES, Ângela; ESTEVES, Manuela. As ciências da educação na obra de Maria Teresa Estrela. Lisboa: Educa, 2015.

CHARLOT, Bernard. Da relação com o saber às práticas educativas. São Paulo: Cortez Editora, 2013.

ESTEVES, Manuela. Professores: profissionalidade(s) a desenvolver. In: Morgado, J.C.; LUNARDI; G. MOREIRA, A. F.; PACHECO; J. A. (Org.). Currículo, internacionalização e cosmopolitismo. Desafios contemporâneos. Santo Tirso: De Facto, 2015. p. 321-332.

FELOUZIS, Georges; MAROY, Christian; ZANTEN, Agnés van. Les marchés scolaires. Sociologe d'une politique publique d'éducation. Paris: PUF, 2013.

FRANKFURT, Harry G. Sobre a desigualdade. Lisboa: Gradiva, 2016.

GOODSON, Ivor. As políticas de currículo e de escolarização. Petrópolis: Editora Vozes, 2008.

O currículo em mudança. Estudos na construção social do currículo. Porto: Porto Editora, 2001.

HARGREAVES, Andy; FULlAN, Michael. Professional capital. Transforming teaching every school. London: Routledge, 2012.

HORKHEIMER, Max. O eclipse da razão. Lisboa: Antígona, 1944/2014.

LIBÂNEO, José Carlos. Ensinar e aprender, aprender a ensinar: o lugar da teoria e da prática em didática. In: LIBÂNEO, J. C.; ALVES, N. (Org.). Temas de pedagogia. Diálogos entre didática e currículo. São Paulo: Cortez Editora, 2012. p. 35-60.

Políticas educacionais no Brasil: desfiguramento da escola e do conhecimento escolar. Cadernos de Pesquisa, v. 46 , n. 159 , p. 38-63, 2016.

LIPOVETSKY. Gilles. A sociedade da deceção. Lisboa: Edições 70, 2012.

LUNARDI, Geovana. Tecnologia é a resposta, mas qual era a questão? Sobre políticas de inserção de tecnologias nas escolas e mudanças curriculares. In: Morgado; J.C., LUNARDI; G. MOREIRA, A. F.; PACHECO; J. A. (Org.). Currículo, internacionalização e cosmopolitismo. Desafios contemporâneos. Santo Tirso: De Facto, 2015. p. 321-332.

MANNENT, Pierre. História intelectual do liberalismo. Dez lições. Lisboa: Edições 70, 2015.

MAROY, Christian. Towards post-bureaucratic modes of governance. In: STEINER-KHAMSI, G.; WALDOW, F. (Eds.). World yearbook of education 2012. Policy borrowing and lending in education. London: Routledge, 2012, p. 6293.

MERGLER, Amanda; CARRINGTON, Suzanne; KIMBER, Megan; BLAND, Derek. Inclusive values: exploring the perspectives of pre-service teachers. Australian Journal of Teacher Education, v. 41, n. 4, p. 19-38, 2016.

MORGADO, José Carlos. Currículo e formação continua de professores em Portugal: dissonâncias entre discursos e práticas. In: OLIVEIRA, M. R. (Org.). Professor, formação, saberes e problemas. Porto: Porto Editora, 2014. p. 67-90.

PACHECO, José A. Educação, formação e conhecimento. Porto: Porto Editora, 2014. 
PACHECO, José A. Flexibilização curricular: algumas interrogações. In. PACHECO, J. A. (Org.). Políticas de integração curricular. Porto: Porto Editora, 2000. p. 127-145.

Para a noção de transformação curricular. Cadernos de Pesquisa, v.64, n. 159, p. 64-77, 2016.

; MARQUES, Micaela. Governamentalidade curricular: ação dos professores em contextos de avaliação externa. In: OLIVEIRA, M. R. (Org.). Professor: formação, saberes e problemas. Porto: Porto Editora, 2014. p. 105-136.

PERRENOUD, Philip. Ofício do aluno e sentido do trabalho escolar. Porto: Porto Editora, 1995.

PINAR, William F. O que é a teoria curricular? Porto: Porto Editora, 2007.

Educational experience as lived: knowledge, history, alterity. The selected works of William F. Pinar. New York: Routledge, 2015.

RIOS, Terezinha. Ética na docência universitária. A caminho de uma diversidade pedagógica? In: PIMENTA, S. G.; ALMEIDA, M. I. (Org.). Pedagogia universitária. Caminhos para a formação de professores. São Paulo: Cortez Editora, 2011.

ROLDÃO, Maria do Céu. Diferenciação curricular revisitada. Conceito, discurso e práxis. Porto: Porto Editora, 2003.

SANTOS, Lucíola Licínio. Currículo e gestão escolar. In: MORGADO, J.C.; LUNARDI, G.; MOREIRA, A.F.; PACHECO, J.A. (Org.). Currículo, internacionalização e cosmopolitismo. Desafios contemporâneos. Santo Tirso: De Facto, 2015. p. 233-240.

SEABRA, Filipa. Empréstimo de políticas curriculares em Portugal (2011-2014). In: Morgado, J.C.; LUNARDI; G. MOREIRA, A.F.; PACHECO; J.A. (Org.). Currículo, internacionalização e cosmopolitismo. Desafios contemporâneos. Santo Tirso: De Facto, 2015. p. 71-80.

SOUSA, Francisco. Diferenciação curricular e deliberação docente. Porto: Porto Editora, 2003.

STEINER-KHAMSI, Gita. Understanding policy borrowing and lending. Building comparative policy studies. In: STEINER-KHAMSI, G. ; WALDOW, F. (Eds.). World yearbook of education 2012. Policy borrowing and lending in education. London: Routledge, 2012. p. 5-17.

THIESSEN, Juares da Silva. Deslocamentos de estratégias e mecanismos de controlo do currículo: implicações em contextos de gestão educacional e escolar. In: MORGADO, J.C.; LUNARDI, G.; MOREIRA, A. F.; PACHECO; J. A. (Org.). Currículo, internacionalização e cosmopolitismo. Desafios contemporâneos. Santo Tirso: De Facto, 2015. p. 213-222.

WIEVIORKA, Michel. A diferença. Lisboa: Fenda, 2002.

YOUNG, Michael F. Por que o conhecimento é importante para as escolas do século XXI? Cadernos de Pesquisa, v. 46, n. 159 159, p. 18-37, 2016.

YOUNG, Michael F. Overcoming the crisis in curriculum theory. A knowledge-based approach. Journal of Curriculum Studies, v. 45, n. 2 , p 101-118, 2013.

ŽIŽEK, Slavoj. O sujeito incómodo. O centro ausente da ontologia política. Lisboa: Relógio D’Água, 2009. 


\section{RESUMO}

Neste artigo aborda-se a inclusão partir de (in)variantes educacionais e curriculares tendo como objeto de problematização não só a discussão de termos, que são usados de forma geral na escola e em documentos internacionais e nacionais, as políticas curriculares, os processos com influência na organização, bem como a tipologia de alunos no contexto escolar. Argumenta-se que o currículo é profundamente desigual, sobretudo devido à sua organização, com tendência para a uniformização e estandardização, pelo que a discriminação é intrínseca às escolas, não podendo ser afastados os fatores socioeconómicos. A inclusão educativa é, pela sua natureza de percursos, uma questão curricular que tem de ser repensada a partir de invariantes educacionais, existentes nas práticas escolares, com o reconhecimento de que a diversidade é um dos princípios fundamentais do desenvolvimento do currículo.

Palavras-chave: Inclusão, Currículo, Diversidade, Desigualdade.

\section{ABSTRACT}

In this article we discuss the inclusion from (in) educational and curricular variants having as problematic object the discussion of terms, that are used in general at school and at national and international documents, the curriculum policies, the processes with influence on the organization, as well as the type of students in the school context. It is argued that the curriculum is profoundly unequal, mainly due to its organization, with a trend towards homogenization and standardization, so that discrimination is intrinsic to schools and cannot be removed socio-economic factors. The educational inclusion is by its nature paths, a curricular issue that has to be rethought from educational invariants, presents in school practices, recognizing that diversity is one of the fundamental principles of curriculum development.

Keywords: Inclusion, Curriculum, Diversity, Inequality.

Submetido abril 2016

Aprovado jun. 2016 